\title{
Eligibility Criteria Met By Subject
}

National Cancer Institute

\section{Source}

National Cancer Institute. Eligibility Criteria Met By Subject. NCI Thesaurus. Code C132447.

An indication that the subject has fulfilled the criteria needed to continue to the next study period. 